\title{
Research on Strategy Control of Taxi Carpooling Detour Route under Uncertain Environment
}

\author{
Wei Zhang, Ruichun He, Qiang Xiao, and Changxi Ma \\ School of Traffic and Transportation, Lanzhou Jiaotong University, Lanzhou 730070, China \\ Correspondence should be addressed to Ruichun He; tranman@163.com
}

Received 25 October 2015; Accepted 21 January 2016

Academic Editor: Lu Zhen

Copyright (C) 2016 Wei Zhang et al. This is an open access article distributed under the Creative Commons Attribution License, which permits unrestricted use, distribution, and reproduction in any medium, provided the original work is properly cited.

For the problem of route choice in taxi carpooling detour, considering the uncertainty of traffic and the characteristic of passengers' noncomplete rationality, an evolutionary game model of taxi carpooling detour route is built, in which prospect theory is introduced and revenue of strategy is replaced by prospect value. The model reflects more really decision-making psychology of passengers. Then the stable strategies of the model are studied, and the influences of detour distance and traffic congestion on detour carpooling success are analyzed, respectively. The results show that when at least one route of which prospect values for two passenger sides are both positive exists, carpooling route can reach an agreement. The route is stable strategy of evolutionary game, and the passengers requiring short travel time tend to select the nondetour route. With the increase of detour distance and traffic congestion rate, the possibility of reaching an agreement decreases gradually; that is, possibility of carpooling failure increases. So taxi carpooling detour is possible under the certain condition, but some measures must be carried out such as constraints of detour distance and mitigation of traffic congestion to improve carpooling success probability. These conclusions have a certain guiding significance to the formulation of taxi carpooling policy.

\section{Introduction}

Taxi carpooling mode is the behavior pattern in which passengers agree to take the same taxi after consultation. The mode can effectively improve the transportation efficiency and ease the traffic pressure, which is an effective solution to solve the urban traffic problem $[1,2]$. Taxi carpooling has become a hot problem in which many scholars are interested.

Many scholars have carried out researches on the problem of carpooling [3-5]. At present, most researches on carpooling are divided into three aspects: firstly, there is the study of the carpooling system, focusing on development tend of carpooling mode, in which empirical research method is used to analyze the implementation situation and the impact factors of carpooling. Shaheen et al. [6] studied market dynamics of North American and carried out quantitative and qualitative analysis of carpooling mode. Chung et al. [7] analyzed carpooling data of 9924 registered members from a carpooling web site in Taiwan, studied the carpooling characteristics of Taiwan residents, and verified that carpooling mode is effective to ease traffic congestion. Buliung et al. [8] analyzed development of carpooling mode in Canada and used logistic regression method to analyze impact factors of carpooling. Wang [9] discussed carpooling mode which is believed to bring some social benefits in China and proposed suggestions for China's carpooling policy according to the current situation. Secondly, there is the study of the carpooling matching and route optimization, in which optimization models are established and heuristic algorithms such as genetic algorithm and ant colony algorithm are designed to solve these models. The optimal matching scheme of the vehicles and passengers and optimal routes are obtained finally. The method is based on the data including the position and destination of passengers and information of drivers from carpooling information platform. Yan et al. [10] proposed route scheduling model and taxi-passenger matching models to solute taxi carpooling problem. Jiau et al. [11] used genetic algorithm to solve the problem of carpooling route matching. Manzini and Pareschi [12] designed a decision support system for carpooling matching. Shao et al. [13] proposed a heuristic clustering algorithm for carpooling demands and the distribution of services. Xiao et al. [14] studied the problem 
of passengers matching based on clustering and pattern recognition method. Thirdly, there is the study of taxi pricing, in which the planning problem of reasonable taxi market price system is researched based on the characteristics of taxi market. The travel rate calculation models are built to analyze the equity of the rate sharing. Most researches were carried out based on the concept of fair carpooling proposed by Fagin and Williams [15] early. Hong [16] established the model of carpooling rate sharing and pricing with starting station and intermediate station, considering passengers fairness. Gong and Yang [17] put forward a method of carpooling cost calculation based on fairness, which can improve taxi drivers' income and reduce passengers' cost. Liu and Zhang [18] designed a small transportation intelligent tool, which includes carpooling pricing chip system, intelligent carpooling bill printing system, driving direction input system, and LED low consumption intelligent display system. Above three aspects are the key problems of taxi carpooling researches.

This paper aims at the problem of taxi carpooling detour route choice. Detour is a common phenomenon in taxi carpooling. Detour may occur when destinations of passengers who ride the same taxi are different. There must be one side passenger who agrees to drive detour route in order to realize carpooling successfully. Taxi carpooling detour route is the route through which passengers reach an agreement to drive after consultation. Of course, the final route is not the best route for passengers selecting detour from the point of travel distance only, but it is the best strategy after comprehensive consideration. Whether passengers will reach an agreement or not is the key of carpooling success. The regulations of carpooling detour route choice have important significance to the formulation of traffic policy.

This paper considers the situation of carpooling route strategy of two passengers whose destinations are different. One of passengers has to choose detour route if the two passengers ride the same taxi successfully. Each passenger faces the two route strategies: detour route and nondetour route. The nondetour route is the shortest route for passenger, and the detour route is the shortest route for the other side. How to decide route for passengers is the key of the research. The two factors including individual psychology and choice of the other passenger will affect decision of passenger. On the one hand passenger tends to select the route closer to his psychological expectation. Moreover the decision-making environment is uncertain because the phenomenon of traffic congestion is common in reality and traffic condition is uncertain, which brings trouble to study passenger's decision. And human being always shows non-full-rationality in decision-making $[19,20]$. Considering uncertainty of decision environment and characteristic of non-full-rationality decision, this paper introduces prospect theory to analyze passenger's decision psychology. Prospect theory proposed by American psychologist Dr. Kahneman is a kind of cross theory of psychology and behavior science [21]. Prospect theory describes decision characteristic of people with nonfull-rationality in uncertain environment [22-24]. It reflects people's decision tendency more really, which suits for the problem of carpooling route decision. On the other hand, carpooling success depends on reaching a route agreement, that is, carpooling failure if the two passengers select different routes. Passenger's decision is affected by choice of the other passenger. The final route strategy is the result of the two passengers' game in fact. Stable strategy is evolution result of the problem, which can help manager to formulate traffic policy. Evolution game theory is a dynamic method of analyzing evolution trend of crowd behavior, which is applied into some fields [25-27]. This paper studies evolution result of route strategy and analyzes stability of evolution result based on evolution game theory.

In summary, game of taxi carpooling detour route is studied based on prospect theory and evolution game theory. Firstly, passenger psychology decision model is built considering travel time and cost, in which comprehensive prospect value of each route is obtained. Secondly, carpooling detour route game model is established, in which comprehensive prospect values revealing passengers' real psychological gains and losses are used as revenue. Then evolutionary strategy and its regularity are analyzed further. At last an example is given to show application of the model; meanwhile influence of detour distance and traffic congestion on stable strategy are analyzed in this paper.

\section{Modeling}

2.1. Problem Description. Suppose two passengers start from the same location $O$. The destination of passenger 1 is $D_{1}$, and destination of passenger 2 is $D_{2}$. The shortest route for passenger 1 is $O D_{1}$, the shortest route for passenger 2 is $O D_{2}$, and $O D_{1} \neq O D_{2}$ as shown in Figure 1. If passengers ride taxi lonely, passenger 1 will select route $O D_{1}$, and passenger 2 will select route $O D_{2}$. Now the two passengers decide to ride the same taxi, then there are two route choices: $O D_{1} D_{2}$ (strategy 1 ) and $O D_{2} D_{1}$ (strategy 2). If driving route is $O D_{1} D_{2}$ starting from $O$, through $D_{1}$, to $D_{2}$, passenger 2 makes a detour. If driving route is $O D_{2} D_{1}$, starting from $O$, through $D_{2}$, to $D_{1}$, passenger 1 makes a detour. The ultimate driving route is jointly decided by the two passengers. There must be one of passengers selecting detour to reach an agreement route if carpooling succeeds. Of course, the detour passenger will cost less fare compensating time delay. The two passengers will make decision according to personal psychological expectation and choice of the other side.

2.2. Passenger Psychology Decision Model. Passenger will consider individual psychological expectation and traffic congestion condition when he makes route choice. Individual psychological expectations about travel time and cost are regarded as the reference points called time reference point and cost reference point, respectively. $k_{u t}$ represents time reference point of passenger $u$, and $k_{u c}$ represents cost reference point of passenger $u$. The condition of traffic congestion $j$ is uncertain, and each route has two states: traffic normal state $(j=1)$ and traffic congestion state $(j=2)$. The probability of route $O D_{1}$ having traffic congestion is $P_{1}$ and route $O D_{2}$ is $P_{2}$.

Set $t_{u i j}$ is travel time of passenger $u(u=1$ represents passenger 1 , and $u=2$ represents passenger 2 ) under the condition of strategy $i$ ( $i=1$ represents strategy 1 , and $i=2$ 


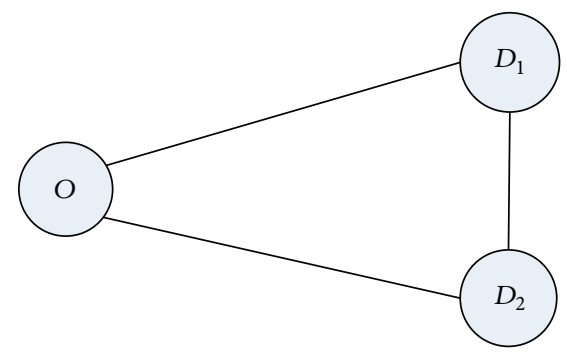

FIGURE 1: Travel routes of carpooling passengers.

represents strategy 2) and traffic state $j$. Time gain of possible travel time relative to time reference point $k_{u t}$ is

$$
y_{u i j}^{t}=k_{u t}-t_{u i j}
$$

Suppose taxi charging standard stipulates that initiate fee is $f_{s} ¥ / a \mathrm{~km}, f_{r} ¥$ per kilometer more than $a$ kilometers, and waiting fee is $f_{q} ¥ / \mathrm{min}$. Then when travel distance is $l$ and waiting time is $r$, cost $Z(l, r)$ is

$$
Z(l, r)= \begin{cases}f_{s}+r f_{q} & \text { if } l \leq a \\ (l-a) f_{r}+f_{s}+r f_{q} & \text { if } l>a .\end{cases}
$$

$c_{u i j}$ is cost of passenger $u$ under the condition of strategy $i$ and traffic state $j$, specifically as follows:

$$
c_{u i j}= \begin{cases}\theta Z\left(l_{u i},(j-1)\left(t_{u i 2}-t_{u i 1}\right)\right) & \text { if } u=i \\ c_{u i j}^{*} & \text { if } u \neq i,\end{cases}
$$

where $c_{u i j}^{*}$ is cost of driving detour route, $\theta$ is carpooling payment ratio which is fee discount for carpooling passenger and $l_{u i}$ is travel distance of passenger $u$ under strategy $i$. When $u=i$ (i.e., passenger $u$ drives nondetour route), $c_{u i j}=\theta Z\left(l_{u i}, 0\right)$ if $j=1$, and $c_{u i j}=\theta Z\left(l_{u i}, t_{u i 2}-t_{u i 1}\right)$ if $j=2$. When $u \neq i$ (i.e., passenger $u$ drives detour route), cost is $c_{u i j}^{*}$. Considering the problem of the detour time is more than nondetour time, the detour cost should be lower than nondetour cost, as given in the following relational expression:

$$
\frac{t_{u u 1}}{t_{u i j}}=\frac{c_{u i j}^{*}}{c_{u u 1}} .
$$

Cost gain of possible cost $c_{u i j}$ for passenger $u$ relative to cost reference point $k_{u c}$ is

$$
y_{u i j}^{c}=k_{u c}-c_{u i j} \text {. }
$$

According to value function form of prospect theory, define value function of scenes $t_{u i j}$ and $c_{u i j}$ as follows:

$$
\begin{aligned}
& v_{u i j}^{t}= \begin{cases}\left(y_{u i j}^{t}\right)^{\alpha} & \text { when } y_{u i j}^{t} \geq 0 \\
-\lambda\left(-y_{u i j}^{t}\right)^{\beta} & \text { when } y_{u i j}^{t}<0,\end{cases} \\
& v_{u i j}^{c}= \begin{cases}\left(y_{u i j}^{c}\right)^{\alpha} & \text { when } y_{u i j}^{c} \geq 0 \\
-\lambda\left(-y_{u i j}^{c}\right)^{\beta} & \text { when } y_{u i j}^{c}<0,\end{cases}
\end{aligned}
$$

where $\alpha$ and $\beta(0 \leq \alpha, \beta \leq 1)$ are risk attitude coefficients. The bigger $\alpha$ and $\beta$ are, the more adventurous decision maker tends. $\lambda(\lambda>1)$ is loss aversion coefficient, which reflects that decision maker is more sensitive to loss. Value function shows the decreasing sensitivity in the two directions of gain and loss, which reflects the psychological revenue more really. The parameters values $\alpha=0.89, \beta=0.92$, and $\lambda=2.25$ are more consistent with psychological characteristic of decision maker.

The probability of traffic congestion passenger perceived is not actual probability according to prospect theory. Set $p_{i j}$ is actual probability of route strategy $i$ under traffic state which is $j$, so $p_{11}=1-p_{1}, p_{12}=p_{1}, p_{21}=1-p_{2}, p_{22}=p_{2}$, and probability of traffic congestion passenger perceived is

$$
\begin{aligned}
& W^{+}\left(p_{i j}\right)=\frac{\left(p_{i j}\right)^{\chi}}{\left(\left(p_{i j}\right)^{\chi}+\left(1-p_{i j}\right)^{\chi}\right)^{1 / \chi}}, \\
& W^{-}\left(p_{i j}\right)=\frac{\left(p_{i j}\right)^{\delta}}{\left(\left(p_{i j}\right)^{\delta}+\left(1-p_{i j}\right)^{\delta}\right)^{1 / \delta}},
\end{aligned}
$$

where $W^{+}\left(p_{i j}\right)$ is probability transformation of time gain and $W^{-}\left(p_{i j}\right)$ is probability transformation of time loss. Transformed probability is called scene weight, which is more close to people's subjective probability. The parameter values most reflecting individual behavior of decision maker are $\chi=0.61, \delta=0.69$.

Time prospect value $E V_{u i}^{t}$ and cost prospect value $E V_{u i}^{c}$ of passenger $u$ perceived under the condition of route strategy $i$, respectively, are

$$
\begin{aligned}
& E V_{u i}^{t}=\sum W^{+}\left(p_{i j}\right) v_{u i j}^{t}+\sum W^{-}\left(p_{i j}\right) v_{u i j}^{t}, \\
& E V_{u i}^{c}=\sum W^{+}\left(p_{i j}\right) v_{u i j}^{c}+\sum W^{-}\left(p_{i j}\right) v_{u i j}^{c} .
\end{aligned}
$$

Considering comprehensively travel time and cost, comprehensive prospect value of passenger $u$ perceived under the condition of route strategy $i$ is

$$
E V_{u i}=w_{1} \widehat{E V_{u i}^{t}}+w_{2} \widehat{E V_{u i}^{c}}
$$

where $w_{1}$ is time weight, $w_{2}$ is cost weight, and $w_{1}+w_{2}=1$. The following relational expression needs to be met:

$$
\frac{w_{1}}{w_{2}}=\frac{\left|t_{u i j}\right|_{\min } / k_{u t}}{\left|c_{u i j}\right|_{\min } / k_{u c}}
$$

In the formula, $\left|t_{u i j}\right|_{\min }=\min \left\{t_{u i j}\right\},\left|c_{u i j}\right|_{\min }=\min \left\{c_{u i j}\right\}$.

Time prospect value $E V_{u i}^{t}$ and cost prospect value $E V_{u i}^{c}$ are standardized as follows to eliminate the influence of different dimensions on calculation result:

$$
\begin{aligned}
& \widehat{E V_{u i}^{t}}=\frac{E V_{u i}^{t}}{\left|E V_{u i}^{t}\right|_{\max }}, \\
& \widehat{E V_{u i}^{c}}=\frac{E V_{u i}^{c}}{\left|E V_{u i}^{c}\right|_{\max }} .
\end{aligned}
$$


TABLE 1: Revenue matrix of passengers.

\begin{tabular}{lcc}
\hline Passenger 1 & \multicolumn{3}{c}{ Passenger 2 } \\
& Strategy 1 & Strategy 2 \\
\hline Strategy 1 & $E V_{11}, E V_{21}$ & 0,0 \\
Strategy 2 & 0,0 & $E V_{12}, E V_{22}$ \\
\hline
\end{tabular}

In the formula, $\left|E V_{u i}^{t}\right|_{\max }=\max \left\{E V_{u i}^{t}\right\},\left|E V_{u i}^{c}\right|_{\max }=$ $\max \left\{E V_{u i}^{c}\right\}$, and $-1 \leq \widehat{E V_{u i}^{t}}, \widehat{E V_{u i}^{c}} \leq 1$.

Comprehensive prospect value of strategy reflects actually psychology gain of passenger. The greater $E V_{u i}$, the greater gain of passenger $u$ for strategy $i$.

2.3. Carpooling Route Evolution Game Based on Comprehensive Prospect Value. The two passengers both face two route strategies: strategy 1 (route $O D_{1} D_{2}$ ) and strategy 2 (route $O D_{2} D_{1}$ ). The choice of route is not only related to individual expectation, but also impacted by the other passenger's decision. In fact it is a game process. Game model of two passengers is established. Because prospect value can reflect passenger's psychology more really, comprehensive prospect value of each strategy for each passenger is regarded as revenue in the game model. The specific revenue matrix is shown in Table 1 (revenue is 0 in carpooling failure).

Suppose the proportion of passengers selecting strategy 1 of passenger 1 type is $p$, and the proportion of passengers selecting strategy 1 of passenger 2 type is $q$. Subject expectation gains of strategy 1 and strategy 2 for passenger 1 , respectively, are

$$
\begin{aligned}
& u_{11}=E V_{11} q, \\
& u_{12}=E V_{12}(1-q) .
\end{aligned}
$$

$$
J=\left[\begin{array}{cc}
(1-2 p)\left(E V_{11} q-E V_{12}(1-q)\right) & p(1-p)\left(E V_{11}+E V_{12}\right) \\
q(1-q)\left(E V_{21}+E V_{22}\right) & (1-2 q)\left(E V_{21} p-E V_{22}(1-p)\right)
\end{array}\right]
$$

Next we analyze stability of equilibrium points based on Jacobian matrix, as shown in Table 2. From Table 2, equilibrium points $(0,0),(0,1),(1,0)$, and $(1,1)$ are likely to be stable points. $(0,0)$ or $(1,1)$ is evolutionary stable point of system when any strategy gain of each passenger is positive, which means that passengers reach an agreement and carpooling succeeds; $(0,1)$ or $(1,0)$ is evolutionary stable point of system when any strategy gain of each passenger is negative, which means that passengers could not agree to drive the same route and carpooling fails.

Based on above analysis, there are four possible stable points in system: $(0,0),(0,1),(1,0)$, and $(1,1)$. Figure 2 shows replication dynamic relationship and stability of two passengers. $(1,1)$ is stable point when $E V_{11}>0, E V_{21}>0$,
Average expectation gain is

$$
\begin{aligned}
\bar{u}_{1} & =u_{11} p+u_{12}(1-p) \\
& =E V_{11} q p+E V_{12}(1-q)(1-p) .
\end{aligned}
$$

Replication dynamic equation of proportion of passenger 1 type is

$$
\begin{aligned}
F(p) & =\frac{d p}{d t}=p\left(u_{11}-\bar{u}_{1}\right) \\
& =p(1-p)\left(E V_{11} q-E V_{12}(1-q)\right)
\end{aligned}
$$

Subject expectation gains of strategy 1 and strategy 2 for passenger 2, respectively, are

$$
\begin{aligned}
& u_{21}=E V_{21} p, \\
& u_{22}=E V_{22}(1-p) .
\end{aligned}
$$

Average expectation gain is

$$
\begin{aligned}
\bar{u}_{2} & =u_{21} q+u_{22}(1-q) \\
& =E V_{21} p q+E V_{22}(1-p)(1-q) .
\end{aligned}
$$

Replication dynamic equation of proportion of passenger 2 type is

$$
\begin{aligned}
F(q) & =\frac{d q}{d t}=q\left(u_{21}-\bar{u}_{2}\right) \\
& =q(1-q)\left(E V_{21} p-E V_{22}(1-p)\right) .
\end{aligned}
$$

The equilibrium points of evolution system are $(0,0),(0$, $1),(1,0),(1,1)$, and $\left(p^{*}, q^{*}\right)$, in which $\left(p^{*}, q^{*}\right)$ is saddle point, $p^{*}=E V_{22} /\left(E V_{21}+E V_{22}\right)$, and $q^{*}=E V_{12} /\left(E V_{11}+E V_{12}\right)$.

Jacobian matrix is

$\left(E V_{12}<0 \mid E V_{22}<0\right),\left(E V_{11} / E V_{12}\right)>-1$, and $\left(E V_{21} / E V_{22}\right)>$ -1 , as shown in Figure 2(a). $(0,0)$ is stable point when $E V_{12}>$ $0, E V_{22}>0,\left(E V_{11}<0 \mid E V_{21}<0\right),\left(E V_{11} / E V_{12}\right)>-1$, and $\left(E V_{21} / E V_{22}\right)>-1$, as shown in Figure 2(b). (0, 0) and (1, 1) are likely to be stable points when $E V_{11}>0, E V_{12}>0$, $E V_{21}>0$, and $E V_{22}>0$, as shown in Figure 2(c). The ultimate stable strategy depends on initial value of $(p, q)$. If initial $(p, q)$ falls within the OXZYO area, namely, $p<p^{*}$, $q<\left(\left(q^{*}-1\right) / p^{*}\right) p+1$ or $p>p^{*}, q<\left(q^{*} /\left(p^{*}-1\right)\right)(p-1)$, stable strategy is $(0,0)$; if initial $(p, q)$ falls within the UXZYU area, namely, $p<p^{*}, q>\left(\left(q^{*}-1\right) / p^{*}\right) p+1$ or $p>p^{*}$, $q>\left(q^{*} /\left(p^{*}-1\right)\right)(p-1)$, stable strategy is $(1,1)$. Similarly $(0,1)$ is stable point when $E V_{11}<0, E V_{22}<0,\left(E V_{12}>0\right.$ । $\left.E V_{21}>0\right),\left(E V_{11} / E V_{12}\right)>-1$, and $\left(E V_{21} / E V_{22}\right)>-1$, as 
TABLE 2: Stability analysis.

\begin{tabular}{lcc}
\hline Equilibrium point & $\operatorname{Det}(J)$ & $\operatorname{Tr}(J)$ \\
\hline$(0,0)$ & $E V_{12} \cdot E V_{22}$ & $-E V_{12}-E V_{22}$ \\
$(0,1)$ & $E V_{11} \cdot E V_{22}$ & $E V_{11}+E V_{22}$ \\
$(1,0)$ & $E V_{12} \cdot E V_{21}$ & $E V_{12}+E V_{21}$ \\
$(1,1)$ & $E V_{11} \cdot E V_{21}$ & $-E V_{11}-E V_{21}$ \\
$\left(p^{*}, q^{*}\right)$ & $-\frac{E V_{11} E V_{12} E V_{21} E V_{22}}{\left(E V_{11}+E V_{12}\right)\left(E V_{21}+E V_{22}\right)}$ & 0 \\
\hline
\end{tabular}

shown in Figure 2(d). $(1,0)$ is stable point when $E V_{12}<0$, $E V_{21}<0,\left(E V_{11}>0 \mid E V_{22}>0\right),\left(E V_{11} / E V_{12}\right)>-1$, and $\left(E V_{21} / E V_{22}\right)>-1$, as shown in Figure $2(\mathrm{e}) .(0,1)$ and $(1,0)$ are likely to be stable strategies when $E V_{11}<0, E V_{12}<0$, $E V_{21}<0$, and $E V_{22}<0$, as shown in Figure 2(f). If initial $(p, q)$ falls within the OZUYO area, stable strategy is $(0,1)$; if initial $(p, q)$ falls within the OZUXO area, stable strategy is $(1$, $0)$.

Among them, Figures 2(a)-2(c) reflect the result of reaching route agreement and carpooling success, and Figures 2(d)-2(f) reflect the result of carpooling failure. It is required to meet one of the following two conditions to reach an agreement: (1) two passengers feel gain for the same strategy, and gain of one passenger is significantly less than the other passenger for the strategy; (2) two passengers feel gain for each strategy.

\section{Example Analysis}

Taking taxi charging standard of a city as example, initiate fee is $10 ¥ / 3 \mathrm{~km}, 1.4 ¥$ per kilometer more than 3 kilometers, and waiting fee is $1.2 ¥ / 2.5 \mathrm{~min}$. Two passengers ride the same taxi from the same location $O$. The destination of passenger 1 is $D_{1}$, and that of passenger 2 is $D_{2}$. Each passenger has two route strategies to choose: strategy 1 (route $O D_{1} D_{2}$ ) and strategy 2 (route $O D_{2} D_{1}$ ). The shortest route of passenger 1 is $\left|O D_{1}\right|=5 \mathrm{~km}$, passenger 2 is $\left|O D_{2}\right|=5 \mathrm{~km}$, and $\left|D_{1} D_{2}\right|$ $=1$ kilometer. According to the vehicle speed of $30 \mathrm{~km} / \mathrm{h}$, if driving route is $O D_{1} D_{2}$, the arrival time is $10 \mathrm{~min}$ when traffic is normal, and the arrival time is $20 \mathrm{~min}$ when traffic congestion occurs for passenger 1 ; the arrival time is $12 \mathrm{~min}$ when traffic is normal, and the arrival time is $24 \mathrm{~min}$ when traffic congestion occurs for passenger 2 . If driving route is $O D_{2} D_{1}$, the arrival time is $10 \mathrm{~min}$ when traffic is normal, and the arrival time is $20 \mathrm{~min}$ when traffic congestion occurs for passenger 2; the arrival time is $12 \mathrm{~min}$ when traffic is normal, and the arrival time is $24 \mathrm{~min}$ when traffic congestion occurs for passenger 1 . So each passenger has four possible time states $\{10,20,12,24\}$, and the corresponding cost states are $\{8,11,7,3\}$. Traffic congestion rate of each route is $p_{1}=p_{2}=$ 0.5 , and carpooling payment ratio is 0.6 . Analyze the four scenes as follows.

Scene 1. Time reference point of passenger 1 is $20 \mathrm{~min}$, and cost reference point is $5 ¥$. Time reference point of passenger 2 is $12 \mathrm{~min}$, and cost reference point is $9 ¥$.
Scene 2. Time reference point of passenger 1 is $24 \mathrm{~min}$, and cost reference point is $7 ¥$. Time reference point of passenger 2 is $22 \mathrm{~min}$, and cost reference point is $6 ¥$.

Scene 3. Time reference point of passenger 1 is $24 \mathrm{~min}$, and cost reference point is $7 ¥$. Time reference point of passenger 2 is $17 \mathrm{~min}$, and cost reference point is $11 ¥$.

Scene 4. Time reference point of passenger 1 is $24 \mathrm{~min}$, and cost reference point is $7 ¥$. Time reference point of passenger 2 is $20 \mathrm{~min}$, and cost reference point is $10 ¥$.

Compute prospect values of each strategy for the two passengers based on the method proposed in this paper in the above four scenes. Tables 3-6 show time prospect values, cost prospect values, the weight ratios of time and cost, and comprehensive prospect values of all strategies for the two passengers in four scenes. In scene 1, comprehensive prospect value of each strategy for each passenger is negative. Strategy 1 could not meet the cost demand of passenger 1 and time demand of passenger 2, and strategy 2 could not meet time and cost demand of the two passengers. Two passengers will choose different route which will cause carpooling failure at last. In scene 2, comprehensive prospect values of strategy 1 for two passengers are positive, and strategy 2 could not meet cost demand of passenger 2 requiring lower cost. Two passengers will choose strategy 1 , and carpooling succeeds at last. In scene 3, comprehensive prospect values of strategy 2 for two passengers are positive. Strategy 1 could not meet time demand of passenger 2 requiring shorter time. Two passengers will choose strategy 2 , and carpooling succeeds at last. In scene 4 , comprehensive value of each strategy for each passenger is positive. Strategy 1 and strategy 2 are both possible stable strategies, and the ultimate result depends on initial probabilities of strategy 1 and strategy 2 selected. Here saddle point $\left(p^{*}, q^{*}\right)=(0.736,0.837)$. Stable strategy is strategy 1 when initial probability meets $p<0.736$, $q>1-0.221 p$ or $p>0.736, q>3.17-3.17 p$; otherwise stable strategy is strategy 2. Dynamic evolution processes of strategies under the condition of different initial probabilities are shown as in Figure 3. Figure 3(a) shows dynamic evolution process when initial probability $(p, q)$ is $(0.8,0.8)$. The strategies of two passengers evolve into (1, 1) ultimately, which means two passengers will reach an agreement and choose strategy 1 to drive. Figure 3(b) shows dynamic evolution process when final probability $(p, q)$ is $(0.5,0.5)$. The strategies of two passengers evolve into $(0$, 0 ) immediately, which means two passengers will reach an agreement and choose strategy 2 to drive.

Considering the difference of different passengers' psychology reference points, comprehensive prospect values of each strategy for different psychology reference points are obtained by simulation. The range of time reference point is from $10 \mathrm{~min}$ to $24 \mathrm{~min}$, and the range of cost reference point is from $3 ¥$ to $11 ¥$ based on the condition of the above example. Comprehensive prospect values of nondetour strategy are shown as in Figure 4, and those of detour strategy are shown as in Figure 5. Comparing Figure 4 with Figure 5, comprehensive prospect value of detour strategy improves obviously compared to that of nondetour strategy 

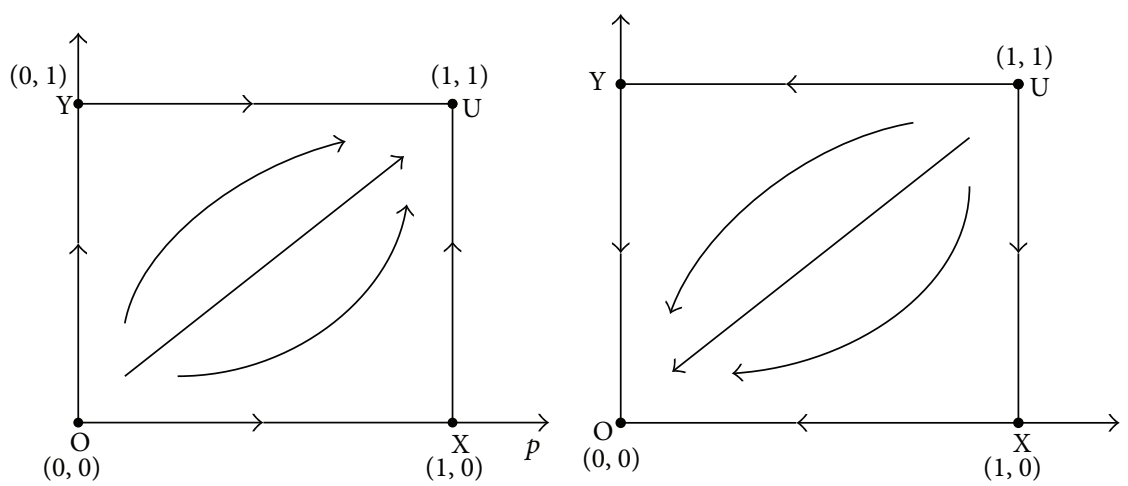

(a) $E V_{11}>0, E V_{21}>0,\left(E V_{12}<0 \mid E V_{22}<0\right)$, $\left(E V_{11} / E V_{12}\right)>-1,\left(E V_{21} / E V_{22}\right)>-1$

(b) $E V_{12}>0, E V_{22}>0,\left(E V_{11}<0 \mid E V_{21}<0\right)$, $\left(E V_{11} / E V_{12}\right)>-1,\left(E V_{21} / E V_{22}\right)>-1$
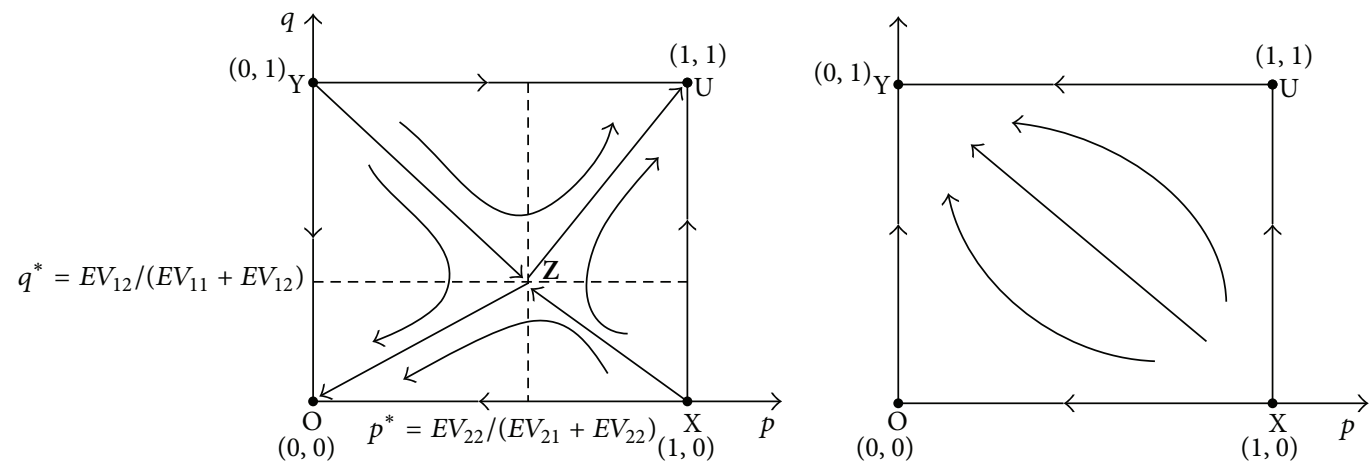

(c) $E V_{11}>0, E V_{12}>0, E V_{21}>0, E V_{22}>0$

(d) $E V_{11}<0, E V_{22}<0,\left(E V_{12}>0 \mid E V_{21}>0\right)$, $\left(E V_{11} / E V_{12}\right)>-1,\left(E V_{21} / E V_{22}\right)>-1$

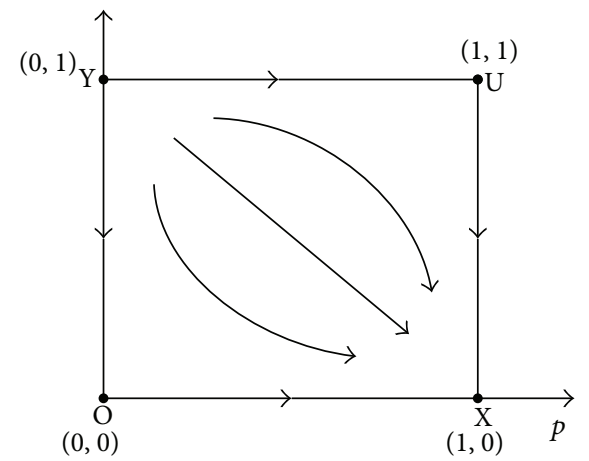

(e) $E V_{12}<0, E V_{21}<0,\left(E V_{11}>0 \mid E V_{22}>0\right)$, $\left(E V_{11} / E V_{12}\right)>-1,\left(E V_{21} / E V_{22}\right)>-1$

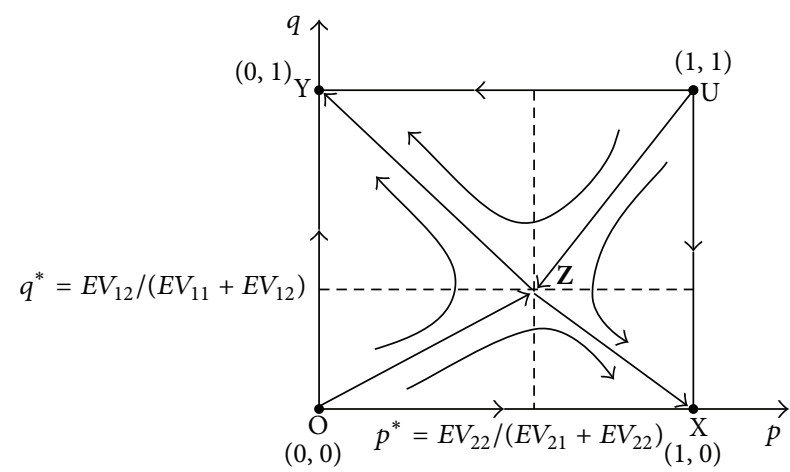

(f) $E V_{11}<0, E V_{12}<0, E V_{21}<0, E V_{22}<0$

FIgURE 2: Replication dynamic relationship and stability of two passengers.

when time reference point is larger and cost reference point is smaller. It reflects that these passengers pursue greater economic interest, not shorter time, and detour strategy could compensate for their loss of time. Although comprehensive prospect values of detour strategy are improved, the value of detour strategy for a part of passengers is still negative; that is, detour strategy cannot make the passengers feel the gain; of course these passengers will not choose detour strategy.

Figure 6 shows reference point range of carpooling success. Carpooling route reaches an agreement when reference points of two passengers fall in the area marked in figure; otherwise carpooling fails. More specifically, stable strategy is strategy 1 when reference point of passenger 1 falls in the area of dotted line and reference point of passenger 2 falls in the area of solid line; conversely stable strategy is strategy 2. The passenger whose reference point falls in the area of solid line will choose detour strategy, and the passenger whose reference points fall in the area of dotted line will choose nondetour strategy. Strategy 1 or strategy 2 will be possible stable strategy when reference points of two passengers fall in the intersection area of solid line and dotted line. Moreover we can see that carpooling route cannot reach an agreement 
TABLE 3: Prospect value of scene 1.

\begin{tabular}{|c|c|c|c|c|c|c|c|}
\hline & \multicolumn{2}{|c|}{ Time prospect value } & \multicolumn{2}{|c|}{ Cost prospect value } & \multirow{2}{*}{$w_{1} / w_{2}$} & \multirow{2}{*}{$E V_{i 1}$} & \multirow{2}{*}{$E V_{i 2}$} \\
\hline & $O D_{1}$ & $\mathrm{OD}_{2}$ & $O D_{1}$ & $\mathrm{OD}_{2}$ & & & \\
\hline Passenger 1 & 3.265 & -0.980 & -8.117 & -1.153 & $5 / 6$ & -2.943 & -1.074 \\
\hline Passenger 2 & -10.048 & -6.140 & 2.851 & -1.512 & $5 / 2$ & -6.362 & -4.818 \\
\hline
\end{tabular}

TABLE 4: Prospect value of scene 2.

\begin{tabular}{|c|c|c|c|c|c|c|c|}
\hline & \multicolumn{2}{|c|}{ Time prospect value } & \multicolumn{2}{|c|}{ Cost prospect value } & \multirow{2}{*}{$w_{1} / w_{2}$} & \multirow{2}{*}{$E V_{i 1}$} & \multirow{2}{*}{$E V_{i 2}$} \\
\hline & $O D_{1}$ & $\mathrm{OD}_{2}$ & $O D_{1}$ & $\mathrm{OD}_{2}$ & & & \\
\hline Passenger 1 & 5.850 & 3.840 & -4.678 & 1.445 & $35 / 36$ & 0.512 & 2.626 \\
\hline Passenger 2 & 1.332 & 4.620 & 0.097 & -6.423 & $10 / 11$ & 0.685 & -1.164 \\
\hline
\end{tabular}

TABLE 5: Prospect value of scene 3.

\begin{tabular}{|c|c|c|c|c|c|c|c|}
\hline & \multicolumn{2}{|c|}{ Time prospect value } & \multicolumn{2}{|c|}{ Cost prospect value } & \multirow{2}{*}{$w_{1} / w_{2}$} & \multirow{2}{*}{$E V_{i 1}$} & \multirow{2}{*}{$E V_{i 2}$} \\
\hline & $O D_{1}$ & $\mathrm{OD}_{2}$ & $O D_{1}$ & $\mathrm{OD}_{2}$ & & & \\
\hline Passenger 1 & 5.850 & 3.840 & -4.678 & 1.445 & $35 / 36$ & 0.512 & 2.626 \\
\hline Passenger 2 & -4.358 & -0.429 & 4.122 & 1.118 & $110 / 51$ & -1.672 & 0.061 \\
\hline
\end{tabular}

TABle 6: Prospect value of scene 4.

\begin{tabular}{lccccrrr}
\hline & \multicolumn{2}{c}{ Time prospect value } & \multicolumn{2}{c}{ Cost prospect value } & \multirow{2}{*}{$w_{1} / w_{2}$} & $E V_{i 1}$ & $E V_{i 2}$ \\
& $O D_{1}$ & $O D_{2}$ & $O D_{1}$ & $D_{2}$ & & $35 / 36$ & 0.512 \\
Passenger 1 & 5.850 & 3.840 & -4.678 & 1.445 & 2.626 \\
Passenger 2 & -0.979 & 3.265 & 3.495 & -0.242 & $5 / 3$ & 0.698 & 1.950 \\
\hline
\end{tabular}

when time demand of passenger is below 17 min because cost discount already cannot compensate for the loss of time. Of course the passengers who do not require shorter travel time will choose detour strategy easily.

Above simulation results are obtained under the condition of detour distance and traffic congestion rate given. Detour distance and traffic congestion rate will affect the decision-making of passengers in the reality. Next the influences of detour distance and traffic congestion rate on carpooling route decision are analyzed, respectively.

3.1. The Influence of Detour Distance on Carpooling Route Strategy. Detour distance $\left|D_{1} D_{2}\right|=1 \mathrm{~km}$ in the above example. Now change detour distance to analyze the influence of detour on carpooling route strategy while else conditions keep unchanged. When detour distance adds to $1.5 \mathrm{~km}$, possible time scene is $\{10,20,13,26\}$ and possible cost scene is $\{8,11,6,3\}$. The reference points of carpooling success reaching an agreement are shown in Figure 7 . It can be seen in the figure that the reference point range in which carpooling strategy can reach an agreement decreases when detour distance is $1.5 \mathrm{~km}$ compared with $1 \mathrm{~km}$ detour distance. And the reference point range of the passengers who select detour strategy also decreases, which indicates the probability of carpooling success decreases.

When detour distance increases to $\left|D_{1} D_{2}\right|=2 \mathrm{~km}$, the reference points of carpooling success are shown in Figure 8. When detour distance increases to $\left|D_{1} D_{2}\right|=2.5 \mathrm{~km}$, the reference points of carpooling success are shown in Figure 9.
When detour distance increases to $\left|D_{1} D_{2}\right|=3 \mathrm{~km}$, the reference points of carpooling success do not exist. Comparing Figures 6-9, the probability of carpooling success decreases gradually with detour distance increase, and carpooling route cannot reach an agreement when detour distance adds to a certain degree.

3.2. The Influence of Traffic Congestion Rate on Carpooling Route Strategy. The traffic congestion rate also has effect on route decision of passengers. Change traffic congestion rate and keep other references unchanged to analyze the influence of traffic congestion on carpooling route strategy. Figures 1014 are in turn reference point range of carpooling success when traffic congestion rate $p=0, p=0.25, p=0.5$, $p=0.75$, and $p=1$. When traffic congestion rate is zero, that is, traffic is normal, the probability of reaching an agreement is the largest. With traffic congestion rate increase, probability of reaching an agreement decreases gradually. When traffic congestion rate is 1 , probability of carpooling success is very little, and carpooling succeeds only if passengers do not require short travel time.

\section{Conclusions}

This paper studies the problem of carpooling detour route choice based on prospect theory and evolutionary game theory, considering the uncertainty of traffic and the characteristic of human noncomplete ration. Passenger's decision psychology is analyzed well, and evolutionary game model 


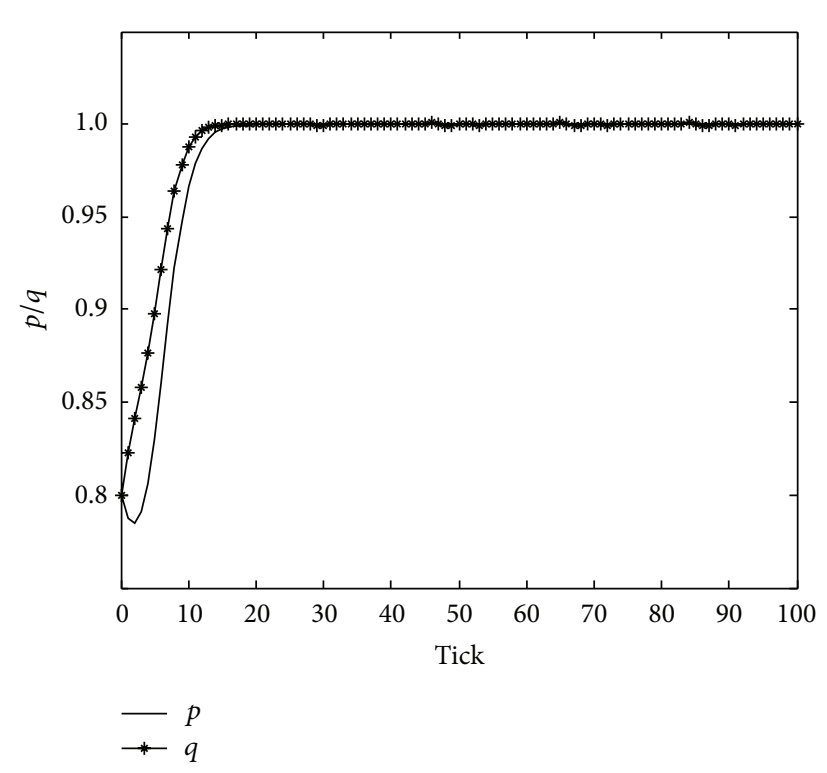

(a) $p=0.8, q=0.8$

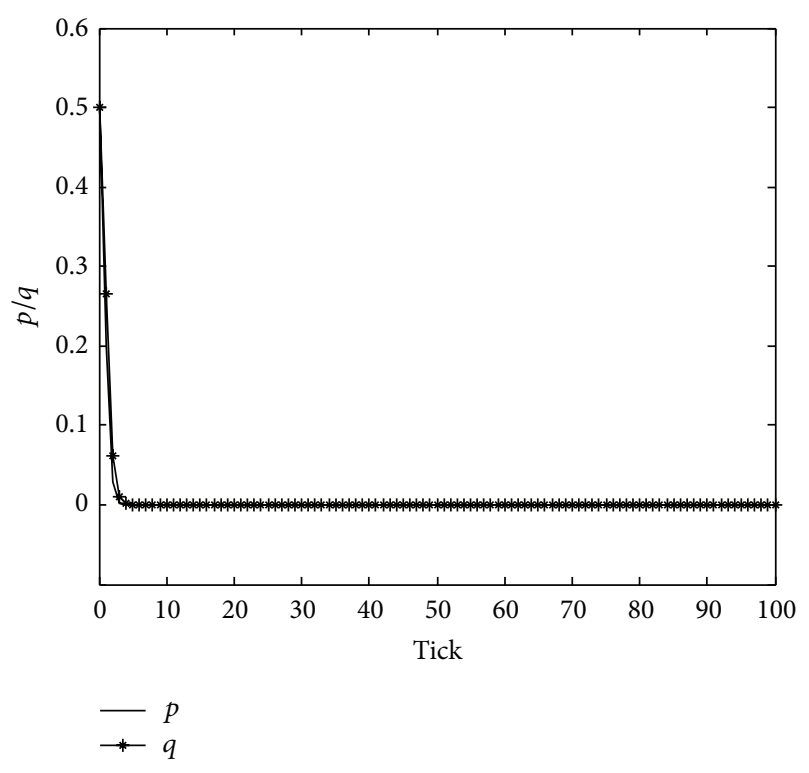

(b) $p=0.5, q=0.5$

FIgURE 3: Strategies dynamic evolution of different initial probabilities.

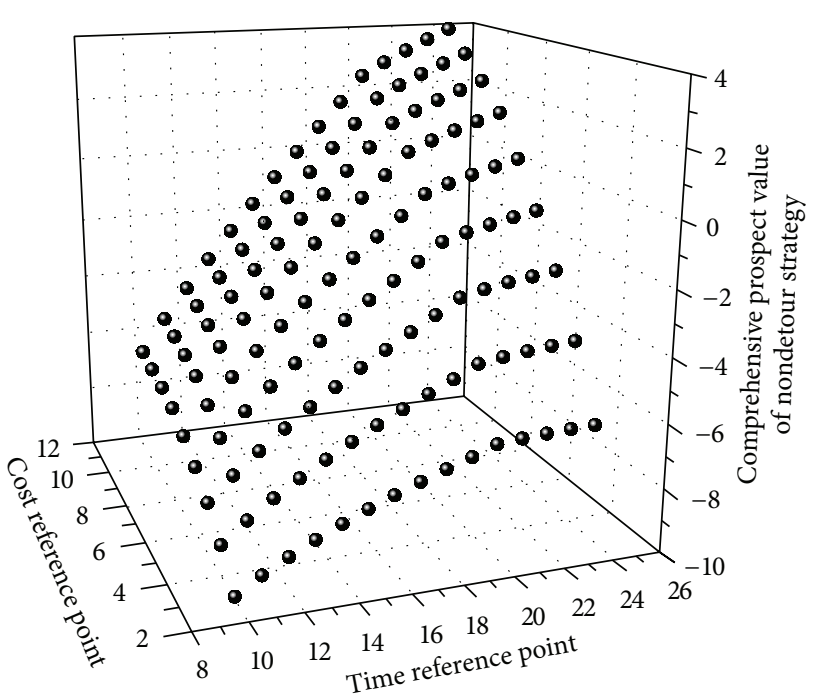

FIGURE 4: Comprehensive prospect values of different reference points for nondetour strategy.

is established. The comprehensive prospect value which can describe psychology gain of passenger is used as revenue of evolutionary game. Stable strategies of detour route and influence regulations of carpooling success are obtained. Conclusions obtained are the following:

(1) There are four stable strategies in taxi carpooling detour system: (detour route, nondetour route), (nondetour route, detour route), (detour route, detour route), and (nondetour route, nondetour route), in which the first two stable strategies mean reaching an agreement and carpooling success. If the two carpooling passengers both feel gain to the same

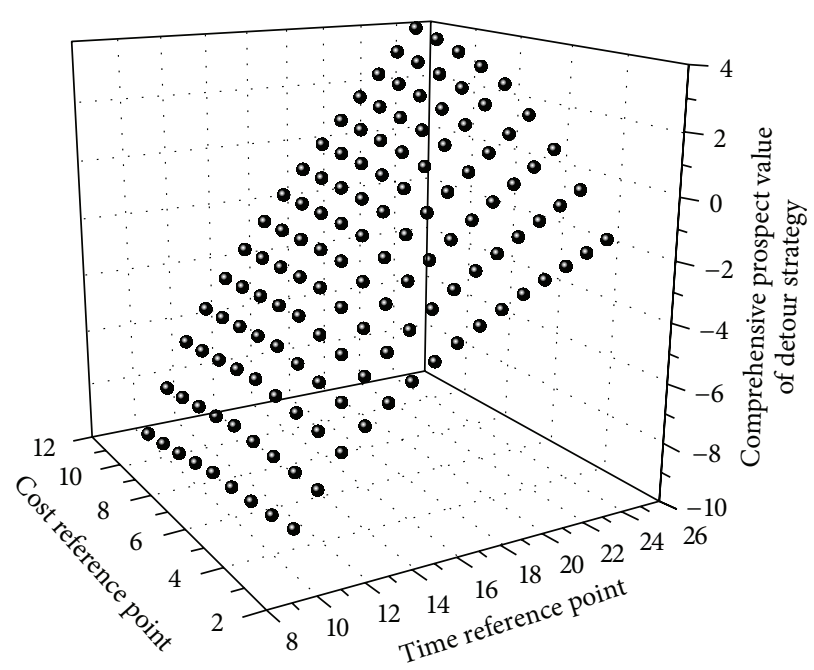

FIGURE 5: Comprehensive prospect values of different reference points for detour strategy.

route, the route is stable strategy. If they both feel gain to the two routes, stable strategy depends on the initial probability of strategy choice of the two types of passengers.

(2) The passengers requiring shorter travel time tend to nondetour strategy; the probability of the passengers who do not require shorter travel time selecting detour strategy is larger. The possibility of passengers selecting detour strategy must be increased in order to improve the probability of detour carpooling success. Decreasing cost of the passenger selecting detour strategy is one of effective measures. 


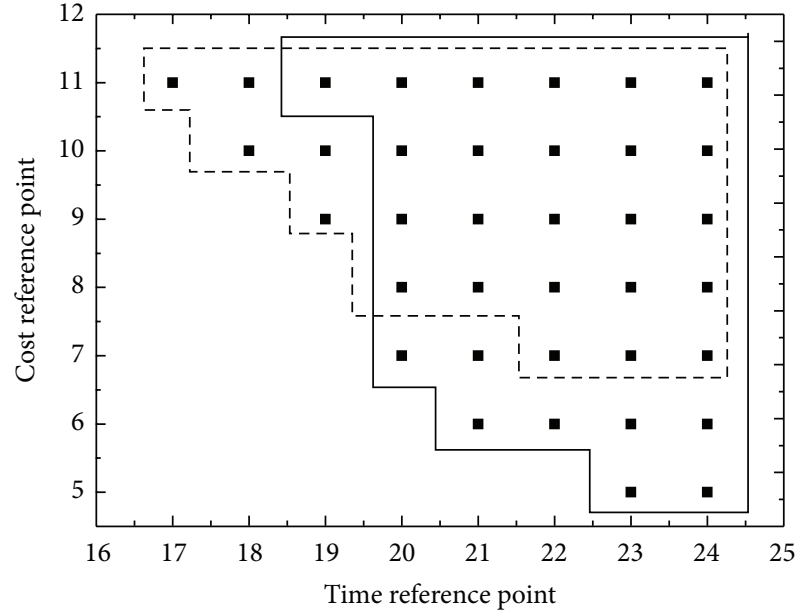

Figure 6: Possible reference points of carpooling success.

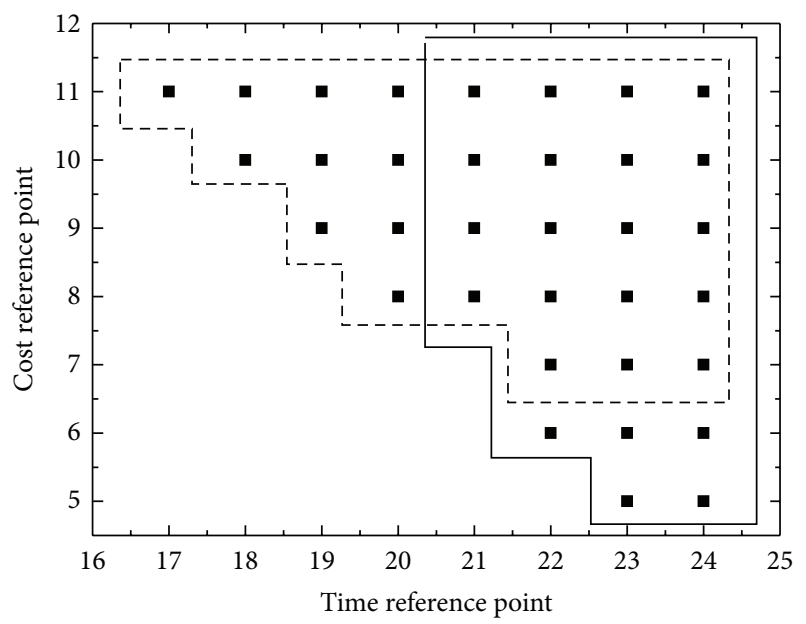

FIgURE 7: Possible reference points of carpooling success with detour distance $1.5 \mathrm{~km}$.

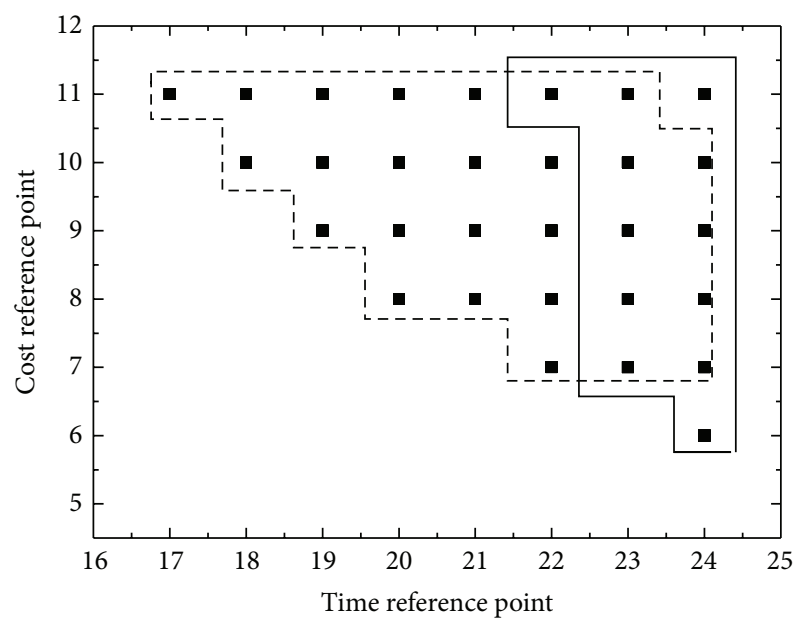

FIGURE 8: Possible reference points of carpooling success with detour distance $2 \mathrm{~km}$.

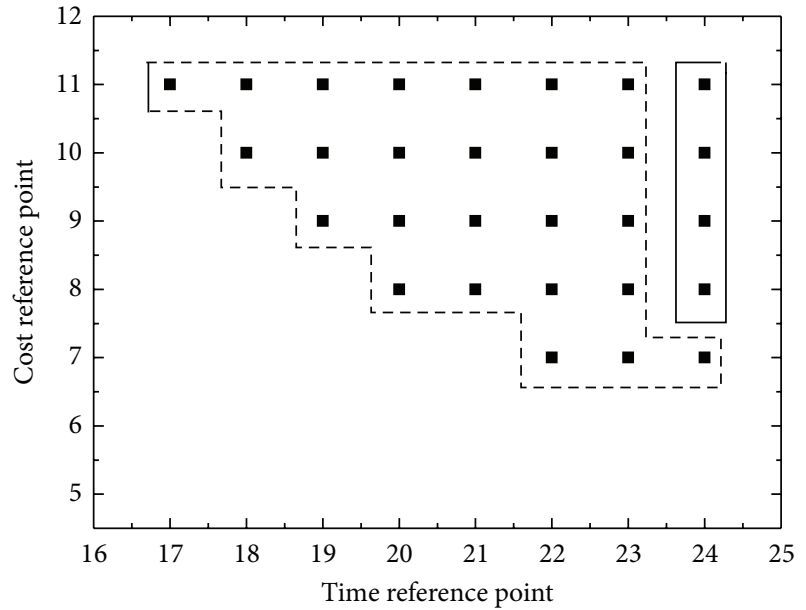

FIgURE 9: Possible reference points of carpooling success with detour distance $2.5 \mathrm{~km}$.

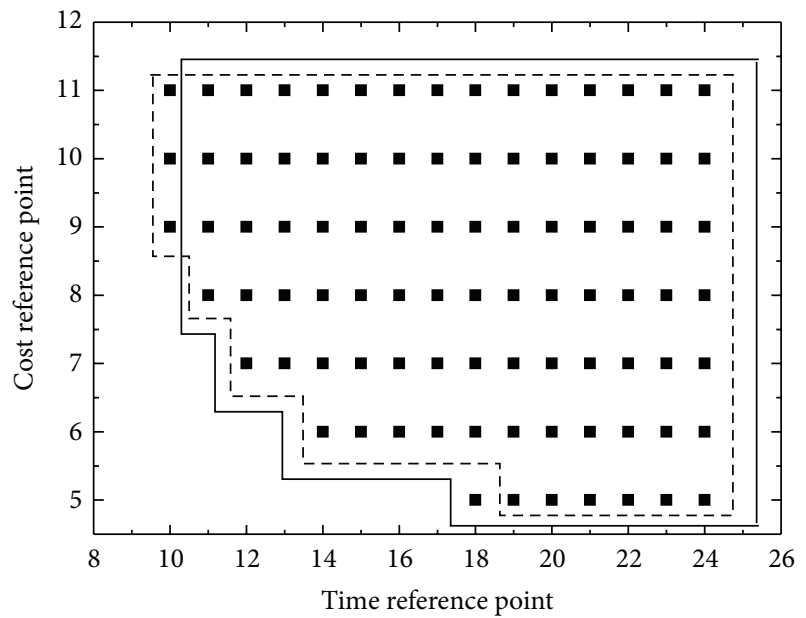

FIGURE 10: Possible reference points of carpooling success with traffic congestion rate 0 .

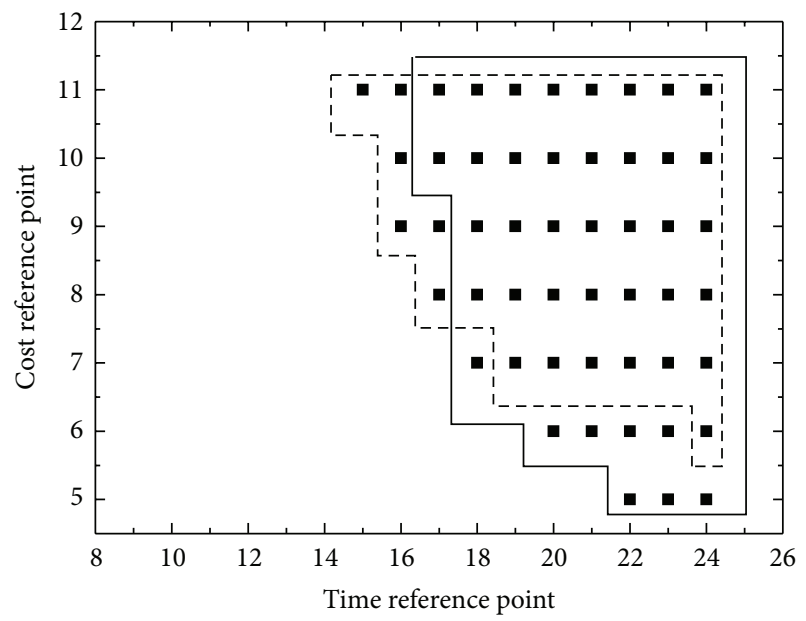

FIGURE 11: Possible reference points of carpooling success with traffic congestion rate 0.25 . 


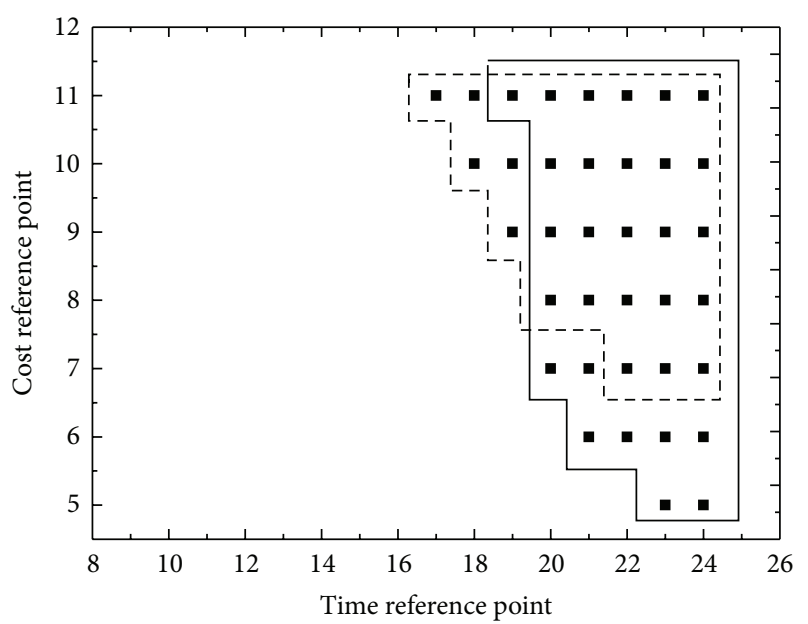

FIGURE 12: Possible reference points of carpooling success with traffic congestion rate 0.5 .

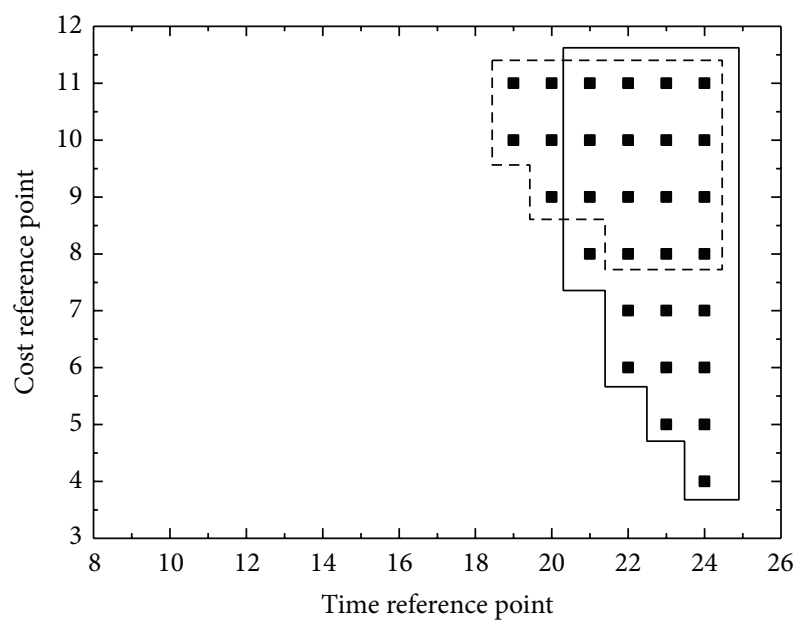

FIGURE 13: Possible reference points of carpooling success with traffic congestion rate 0.75 .

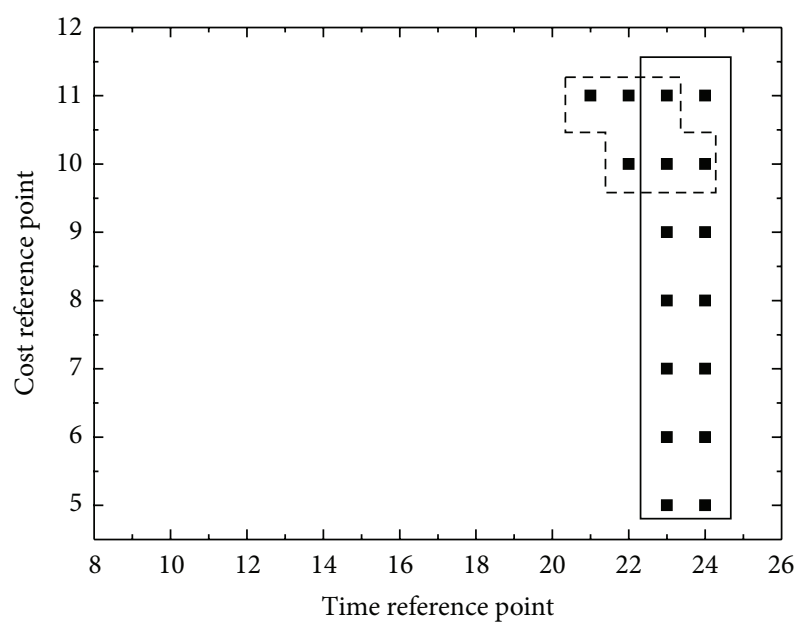

Figure 14: Possible reference points of carpooling success with traffic congestion rate 1.
(3) Detour distance and traffic congestion rate have large influence on passengers' decision. The possibility of carpooling success decreases with detour distance increase. Carpooling route cannot reach an agreement and carpooling fails when detour distance adds to a certain degree. Moreover, the possibility of carpooling success decreases with traffic congestion rate increase. So limit of detour distance and ease traffic congestion are effective method of improving the probability of carpooling success.

In fact, there are some intangible factors affecting passenger's decision, for example, trust in the other party, sex, age of the other party, and day or night. People usually tend to choose detour route in order to take care of old man or child, and people will not choose detour at night. Moreover, information technology also affects passenger's decision. If passenger obtains exact road condition information by intelligent equipment, time and cost are certain. Passenger's decision is not affected by route condition, and decision result is closer to optimization. So development of technology can reduce to a certain extent uncertainty of decision and optimize route choice.

\section{Conflict of Interests}

The authors declare that there is no conflict of interests regarding the publication of this paper.

\section{Acknowledgments}

This research was funded by National Natural Science Foundation of China $(61364026,51408288)$ and Youth Science Foundation of Lanzhou Jiaotong University (2015032). The authors express their thanks to all who participated in this research for their cooperation.

\section{References}

[1] G. Dimitrakopoulos, P. Demestichas, and V. Koutra, "Intelligent management functionality for improving transportation efficiency by means of the car pooling concept," IEEE Transactions on Intelligent Transportation Systems, vol. 13, no. 2, pp. 424-436, 2012.

[2] Y. Q. Lin, W. Q. Li, F. Qiu, and H. Xu, "Research on optimization of vehicle routing problem for ride-sharing taxi," ProcediaSocial and Behavioral Sciences, vol. 43, pp. 494-502, 2012.

[3] Y. T. Chen and C. H. Hsu, "Improve the carpooling applications with using a social community based travel cost reduction mechanism," International Journal of Social Science and Humanity, vol. 3, no. 2, pp. 87-91, 2013.

[4] S. Galland, L. Knapen, A.-U.-H. Yasar et al., "Multi-agent simulation of individual mobility behavior in carpooling," Transportation Research Part C: Emerging Technologies, vol. 45, pp. 83-98, 2014.

[5] Y. Guo, G. Goncalves, and T. Hsu, "A clustering ant colony algorithm for the long-term car pooling problem," International Journal of Swarm Intelligence Research, vol. 3, no. 2, pp. 39-62, 2012. 
[6] S. A. Shaheen, A. P. Cohen, and M. S. Chung, "North American carsharing: 10-year retrospective," Transportation Research Record, vol. 2110, pp. 35-44, 2009.

[7] C. L. Chung, J. Y. Jeng, Z. Y. Lee, and J. S. Lee, "Study of carpool user behaviors and route characteristics in Taiwan," in Proceedings of the 9th Asia Pacific Transportation Development Conference (ASCE '12), pp. 356-363, Chongqing, China, July 2012.

[8] R. N. Buliung, K. Soltys, R. Bui, C. Habel, and R. Lanyon, "Driving factors behind successful carpool formation and use," Transportation Research Record, vol. 2118, pp. 31-38, 2009.

[9] R. Wang, "Shaping carpool policies under rapid motorization: the case of Chinese cities," Transport Policy, vol. 18, no. 4, pp. 631-635, 2011.

[10] S. Yan, C.-Y. Chen, and C.-C. Wu, "Solution methods for the taxi pooling problem," Transportation, vol. 39, no. 3, pp. 723748, 2012.

[11] M.-K. Jiau, S.-C. Huang, and C.-H. Lin, "Optimizing the carpool service problem with genetic algorithm in servicebased computing," in Proceedings of the IEEE 10th International Conference on Services Computing (SCC '13), pp. 478-485, Santa Clara, Calif, USA, July 2013.

[12] R. Manzini and A. Pareschi, "A decision-support system for the car pooling problem," Journal of Transportation Technologies, vol. 2, no. 2, pp. 85-101, 2012.

[13] Z. Z. Shao, H. G. Wang, H. Liu, C. C. Song, C. H. Meng, and H. L. Yu, "Research on service requirement distribution algorithms in carpooling problems," Journal of Tsinghua University, vol. 53, no. 2, pp. 252-258, 2013.

[14] Q. Xiao, R.-C. He, W. Zhang, and C.-X. Ma, "Algorithm research of taxi carpooling based on fuzzy clustering and fuzzy recognition," Journal of Transportation Systems Engineering and Information Technology, vol. 14, no. 5, pp. 119-125, 2014.

[15] R. Fagin and J. H. Williams, "A fair carpool scheduling algorithm," IBM Journal of Research and Development, vol. 27, no. 2, pp. 133-139, 1983.

[16] L. L. Hong, Research on Taxi Pricing Based on Ride-Sharing, Harbin Institute of Technology, Harbin, China, 2012.

[17] X. Z. Gong and Z. Yang, "Study on taxi ridesharing algorithm based fairness principle," Journal of Changsha University, vol. 29, no. 2, pp. 77-80, 2015.

[18] Y. R. Liu and S. Y. Zhang, "Car-pooling pricing model: from perspective of Pareto improvement principle and most easily be translated into implementation," Journal of Central South University (Science and Technology), vol. 44, no. 1, pp. 382-385, 2013.

[19] G. D. M. Ramos, W. Daamen, and S. Hoogendoorn, "Expected utility theory, prospect theory, and regret theory compared for prediction of route choice behavior," Transportation Research Record, vol. 2230, pp. 19-28, 2011.

[20] W. Zhang and R. C. He, "Dynamic route choice based on prospect theory," Procedia-Social and Behavioral Sciences, vol. 138, pp. 159-167, 2014, The 9th International Conference on Traffic and Transportation Studies (ICTTS 2014).

[21] A. Tversky and D. Kahneman, "Advances in prospect theory: cumulative representation of uncertainty," Journal of Risk and Uncertainty, vol. 5, no. 4, pp. 297-323, 1992.

[22] R.-C. Jou and K.-H. Chen, "An application of cumulative prospect theory to freeway drivers' route choice behaviours," Transportation Research Part A: Policy and Practice, vol. 49, pp. 123-131, 2013.
[23] E. Kemel and C. Paraschiv, "Prospect theory for joint time and money consequences in risk and ambiguity," Transportation Research Part B: Methodological, vol. 56, pp. 81-95, 2013.

[24] J. Yang and G. Jiang, "Development of an enhanced route choice model based on cumulative prospect theory," Transportation Research Part C: Emerging Technologies, vol. 47, part 2, pp. 168178, 2014.

[25] C. S. Gokhale and A. Traulsen, "Evolutionary multiplayer games," Dynamic Games and Applications, vol. 4, no. 4, pp. 468488, 2014.

[26] X.-J. Wang, J. Quan, and W.-B. Liu, "Study on evolutionary games and cooperation mechanism within the framework of bounded rationality," System Engineering Theory \& Practice, vol. 31, no. 1, pp. 82-93, 2011.

[27] H. Gong and W. Jin, "Analysis of urban car owners commute mode choice based on evolutionary game model," Journal of Control Science and Engineering, vol. 2015, Article ID 291363, 5 pages, 2015. 


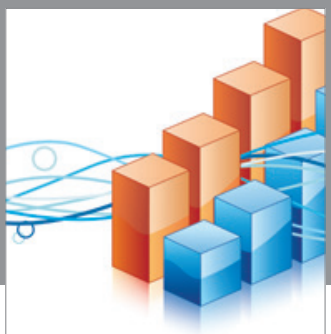

Advances in

Operations Research

vatem alat4

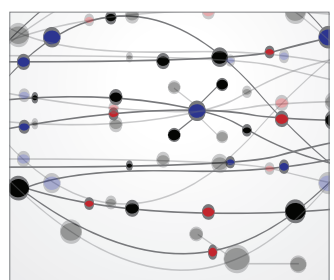

\section{The Scientific} World Journal
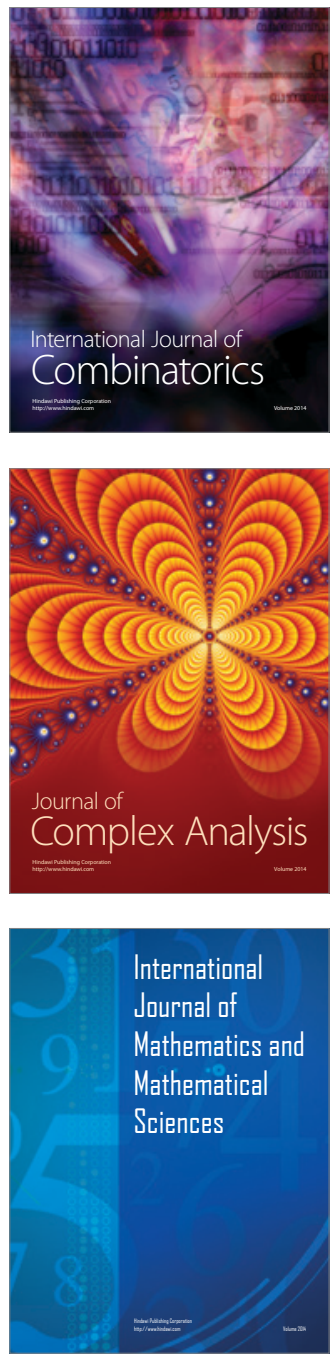
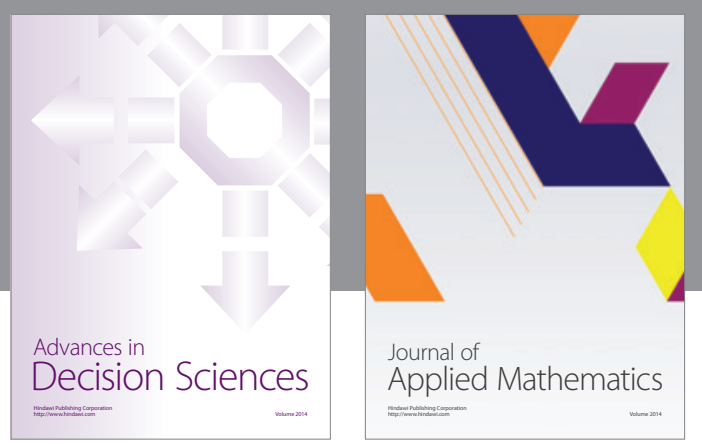

Algebra

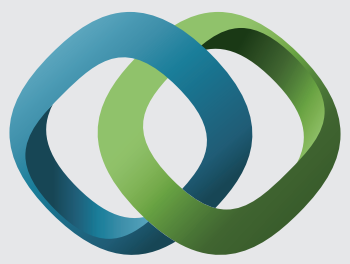

\section{Hindawi}

Submit your manuscripts at

http://www.hindawi.com
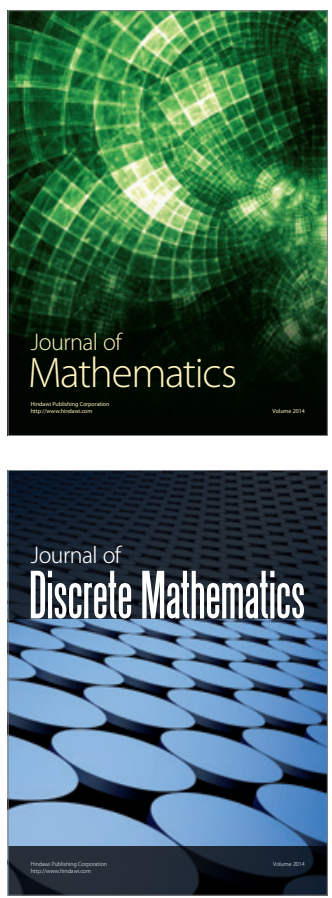

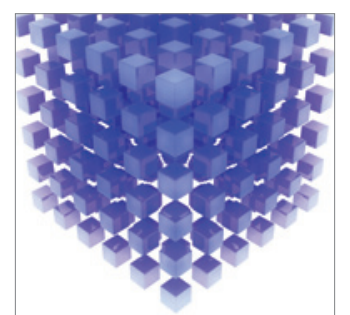

Mathematical Problems in Engineering
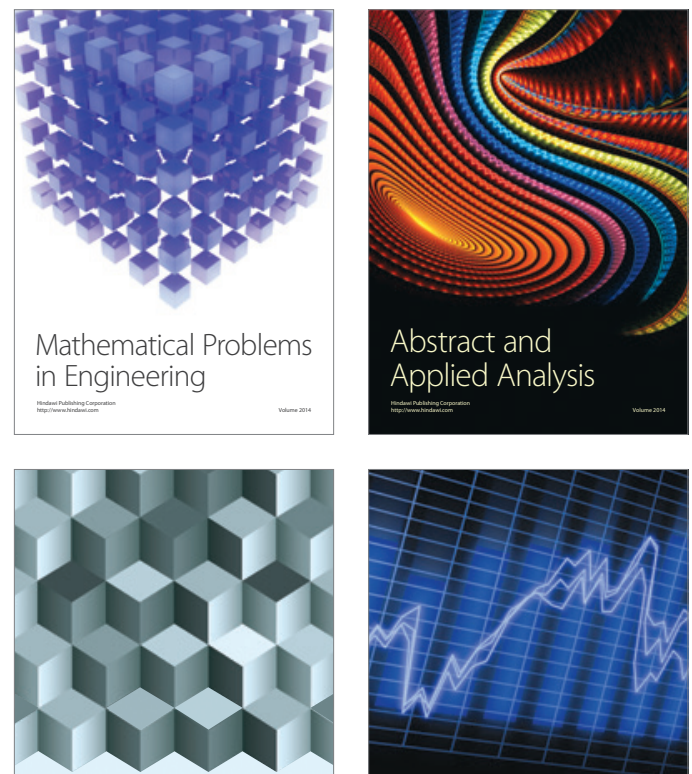

Journal of

Function Spaces

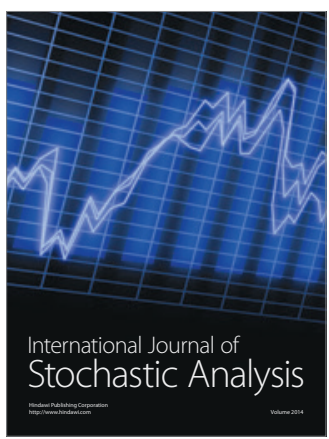

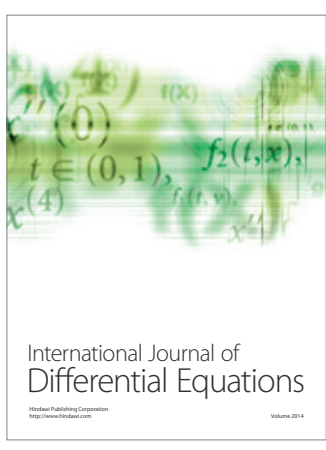
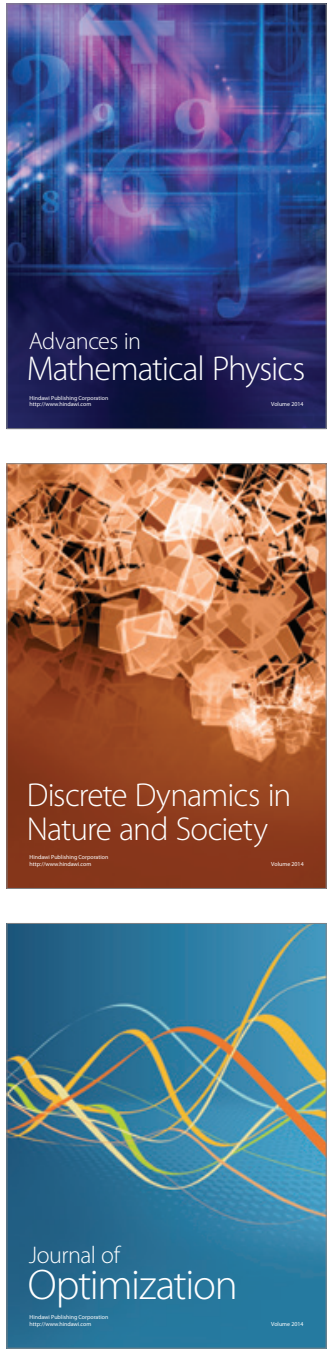